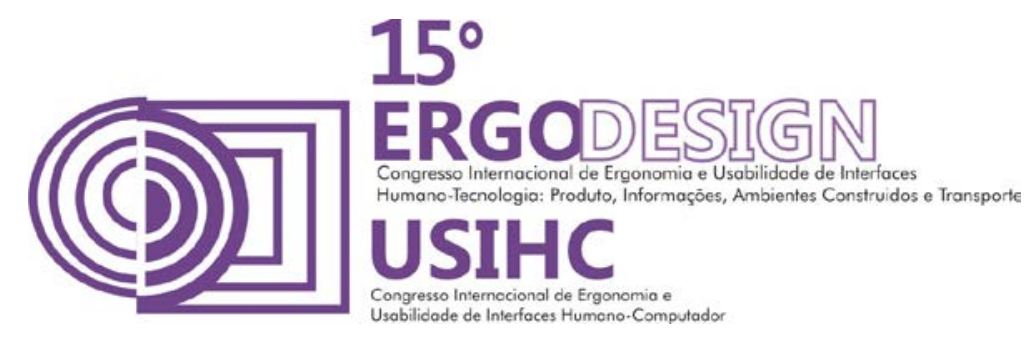

\title{
TECNOLOGIA ASSISTIVA APLICADA A ESCOLARES COM DEFICIÊNCIAS VISUAIS: ESTUDO DE REVISÃO
}

\section{ASSISTIVE TECHNOLOGY APPLIED TO STUDENTS WITH VISUAL DISABILITIES : A REVIEW STUDY}

\author{
CARIZIO, Bethânya Graick (1); \\ NOVAES, Diego Pires (2); \\ ARAÚJO, Adriana Francisca (3); \\ MEDOLA, Fausto Orsi (4); \\ RODRIGUES, Sérgio Tosi (5). \\ PASCOARELLI, Luis Carlos (4)
}

(1)Programa de Pós Graduação em Design, FAAC, UNESP - Bauru. Mestranda.

E-mail: bethanya.carizio@yahoo.com.br

(2) Programa de Pós Graduação em Design, FAAC, UNESP - Bauru. Graduado em Design

E-mail: diegodesign.novaes@gmail.com

(3) Programa de Pós Graduação em Design, FAAC, UNESP - Bauru. Mestranda

E-mail: adrifranci@yahoo.com.br

(4) Programa de Pós Graduação em Design, FAAC, UNESP - Bauru, Professor Doutor.

E-mail: fausto.medola@faac.unesp.br

(5) Programa de Pós Graduação em Design, FAAC, UNESP - Bauru, Professor Doutor.

E-mail: srodrigu@fc.unesp.br

(6) Programa de Pós Graduação em Design, FAAC, UNESP - Bauru, Professor ADJ.

E-mail: luipaschoarelli@faac.unesp.br

\section{RESUMO}

Segundo o Censo de 2010, 18,6\% da população brasileira possuem algum tipo de deficiência visual. Considerando esta grande incidência, o presente estudo objetivou investigar os tipos de tecnologia assistiva para deficientes visuais existentes no Brasil e no mundo a fim de detectar um nicho de atuação do design para futuras contribuições. Foi realizada uma revisão bibliográfica em bases de dados digitais e científicas, analisando estudos publicados de 1994 à 2014. Percebeu-se a carência de recursos que assistam a população com deficiência visual, especialmente no Brasil, embora haja tentativas nem sempre eficazes para atender esta população.

Descritores: tecnologia assistiva; deficiência visual; design universal

\section{ABSTRACT}

According to the 2010 Census, $18.6 \%$ of the Brazilian population have some form of visual impairment. Considering this high incidence, the present study aimed to investigate the types of assistive technology for the visually impaired available in Brazil and the world in order to detect a niche in which the area of design may contribute in the future. A literature review was conducted on digital and scientific databases, 


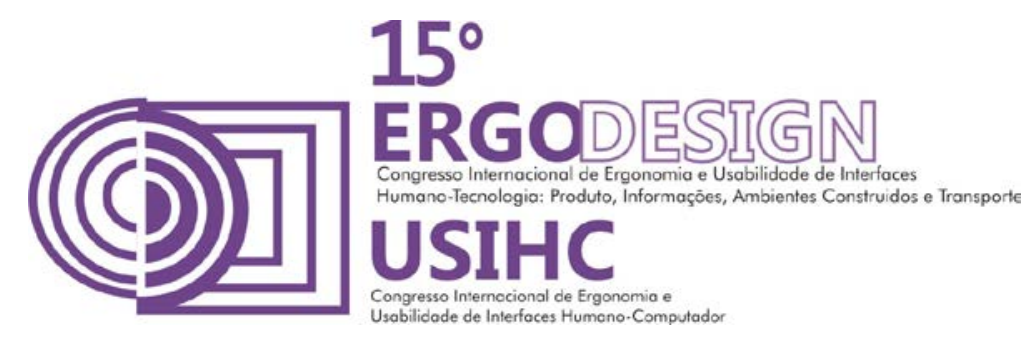

analysing studies published from 1994 to 2014. An insufficience of resources to assist the visually impaired population was observed, especially in Brazil, although attempts with different levels of effectivity to serve this population were evident.

Keywords: assistive technology; visual impairment; universal design

\section{INTRODUÇAO}

A sociedade atual vem passando por diversas transformações tornando-a cada vez mais permeável à diversidade humana, evidenciando uma cosmovisão inclusiva que além de questionar os mecanismos de segregação, permite vislumbrar novos caminhos de inclusão social para todos os indivíduos, entre os quais, as pessoas com deficiência e pessoas idosas. Essa realidade tem se refletido em políticas públicas e programas oficiais, revelando demandas para recursos de Tecnologia Assistiva (TA). As novas orientações e normas estabelecidas para a inclusão educacional de alunos com deficiência na escola regular e os programas nacionais para inclusão sociodigital da população brasileira, veio a contribuir para a pesquisa e elaboração de tecnologia assistiva para atender a diversas populações dentre estas os escolares (GARCIA, GALVÃO, 2012).

Em vista dos avanços tecnológicos conquistados no final do século $X X$, atualmente, o design vem ganhando progressivamente uma maior liberdade na concepção formal dos produtos industrializados, devido aos avanços nos processos produtivos, pesquisas em ergonomia e o surgimento de novos materiais (BONSIEPE, 1986). Neste contexto, é possível considerar um design que contemple de forma mais global as necessidades dos seres humanos em seus diferentes biotipos, cumprindo assim os requisitos do design universal, que objetiva justamente definir projetos de produtos e ambientes que contemplem toda a diversidade humana (CAMBIAGHI, 2007).

Segundo o senso de 2010 feito pelo IBGE (Instituto Brasileiro de Geografia e Estatística), no Brasil existem mais de 45,6 milhões de brasileiros com alguma deficiência, ou seja 23,9\% da população do país. Dentre as deficiências investigadas, a deficiência visual apresentou a maior ocorrência, afetando 18,6\% da população brasileira (IBGE, 2010). Considerando esta grande prevalência de patologias oculares na população brasileira, o presente estudo objetivou investigar quais os tipos de tecnologia assistiva para deficientes visuais existentes no Brasil e no mundo, a fim de discutir os desafios e perspectivas de atuação do design para futuras contribuições neste ramo. Para isto, foi realizado um estudo de revisão de literatura, a partir de buscas em bases de dados (Web of Science, Scielo, Banco de Teses da CAPES, Google Acadêmico) por trabalhos relacionados aos temas deficiência visual e tecnologia assistiva, publicados no período de 1994 a 2014.

\section{REVISÃO DE LITERATURA}

A partir da busca de trabalhos científicos, foram selecionados dez artigos científicos na língua portuguesa, três na língua inglesa, uma tese e uma dissertação, quatro livros e seis sites relacionados ao tema. Os resultados são apresentados e discutidos em seções, conforme organizado abaixo.

\subsection{Definição de tecnologia assistiva}




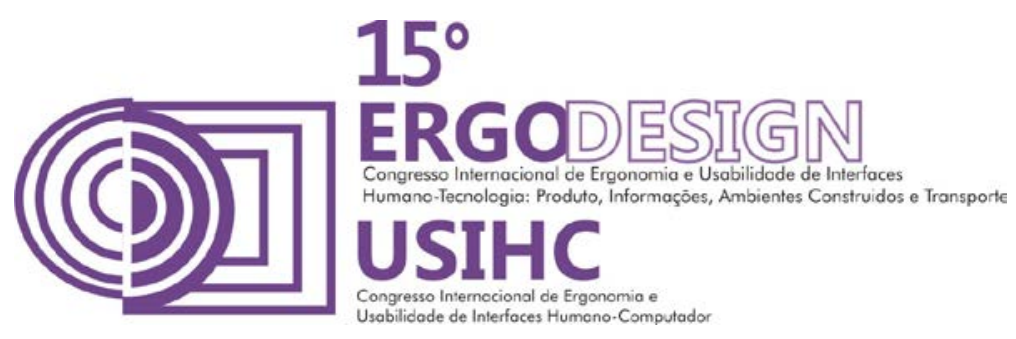

O termo Tecnologia Assistiva (TA) refere-se a uma área do conhecimento de característica interdisciplinar que engloba conceitos de produtos, práticas e serviços, recursos, metodologias, estratégias, objetivando proporcionar a funcionalidade relacionada à atividade e participação de pessoas com deficiência, incapacidades ou com mobilidade reduzida, visando sua autonomia, independência, qualidade de vida e inclusão social (GASPARETTO et al., 2009).

Engenheiros, educadores, terapeutas e designers sabem que os esforços para 0 desenvolvimento e utilização de tecnologia assistiva para pessoas com deficiência são muitas vezes fadados ao fracasso. Boas ideias, associadas a implementações tecnológicas de alta qualidade, resultam em dispositivos que muitas vezes não são utilizados pelo seu público destinado, muitos protótipos não ultrapassam a fase experimental. Observa-se um rechaço, quanto aos produtos especializados, testados e comercializados, acarretando em abandono em torno de 30\% por parte das pessoas com deficiência (PHILLIPS; ZHAO, 1993). Estudos que analisam esse problema sugerem, para amenizá-lo, a implicação das pessoas com deficiência em toda as fases decisivas da produção e a escolha de uso de tais dispositivos (RIEMERREISS \& WACKER, 2000 apud KASTRUP, 2000). Testes de usabilidade, bem como investigação da real necessidade dos diferentes portadores de deficiências, são bem vindos para o sucesso de um produto para tecnologia assistiva.

\subsection{Deficiência Visual: conceitos e caracterização}

Deficiência visual (ou também baixa visão) refere-sea um conjunto de patologias subdivididas em 3 categorias: perda visual moderada, grave e profunda (OMS, 2003). A deficiência visual pode ser congênita e com casuísticas de Retinocoroidite macular por toxoplasmose, Catarata congênita, a Amaurose congênita de Leber, o Glaucoma congênito, entre outras. A baixa visão adquirida tem como etiologia o Descolamento de retina, Glaucoma, Catarata, Degeneração senil de mácula, Diabetes e Traumas oculares (CARVALHO et al., 2002).

O deficiente visual, em geral, ainda encontra muitas barreiras para se integrar plenamente na sociedade moderna, barreiras arquitetônicas no ambiente urbano e domiciliar, barreiras educacionais (falta de adaptação dos materiais didáticos à escrita em Braile)e barreiras econômicas (a não contratação de deficientes visuais para não se ter a incumbência de adaptar o posto de trabalho). Pode-se considerar que a sociedade como um todo não está preparada para acolher e proporcionar uma vida digna a este grupo específico, porém o objetivo deste estudo é pesquisar o que existe no âmbito das TAs, a fim de favorecer a inclusão social do deficiente visual.

\subsection{Tecnologia assistiva para deficientes visuais}

Kastrup (2009) detectou que a população com deficiência visual é bastante heterogenea e a tendência crescente de maior concentração está entre as pessoas idosas. Pesquisas vem avançando timidamente nesta vertente e pouca atenção é dispensada sobre a experiência dos usuários na construção de dispositivos de tecnologia assistiva.

Em sua maioria, os dispositivos de tecnologia assistiva para pessoas com deficiência visual baseiam-se na substitiuição de estímulos de diferentes modalidades sensoriais para compensar a limitação visual. Esta abordagem, denominada substituição sensorial, objetiva auxiliar deficientes visuais a apreenderem fenômenos físicos por meio das modalidades sensoriais 


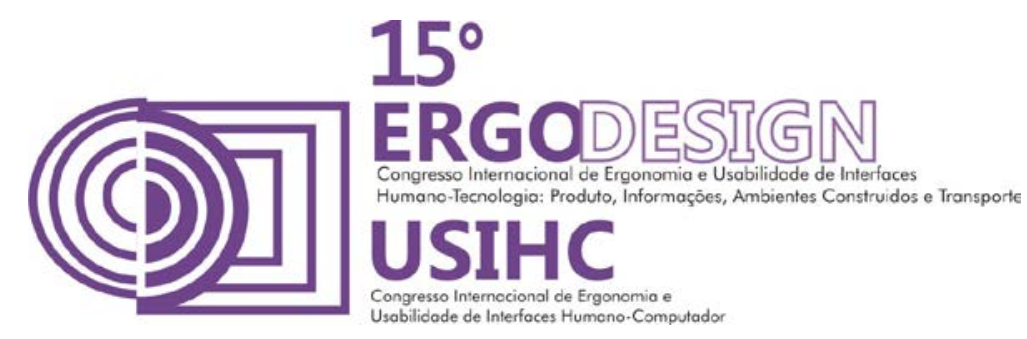

remanescentes. Trata-se, portanto, de recursos que transformam as características de uma modalidade sensorial falha ou inexistente em estímulos de outra modalidade sensorial ativa (GUSMÃO, 2012).

Estudos sobre o aprendizado dos dispositivos de substituição sensorial, de acordo com Kastrup (2009), têm sido baseadas em métodos de terceira pessoa, ou seja, por meio de observação de não usuários, destacando a obtenção de um desempenho com ênfase nas vertentes quantitativas do aprendizado (número de horas, de acertos e erros). Estudos em primeira pessoa, que de acordo com Thompson et al (2005) e Varela ; Shear (1999), são procedimentos programados para que o sujeito consiga acessar e expor sua própria experiência, foram realizados por G. Guarniero (1977), pesquisador cego congênito que relatou sua experiência de treinamento para o uso do dispositivo de substituição sensorial. Em termos metodológicos, o trabalho de Guarniero propõe uma descrição pessoal do processo de aprendizagem, destacando os avanços durante o treino. Discussões recentes têm ressaltado a importância da interação entre métodos de primeira e terceira pessoa para o estudo de aprendizado. Varela e Shear (1999) reuniram trabalhos que expõem métodos em primeira pessoa ultrapassando a mera auto-observação, envolvendo a contribuição de uma segunda pessoa, cujo dever é guiar o processo à experiência. Investigações na área de deficiência visual têm buscado gerar dados em primeira pessoa, por meio de abordagens em segunda pessoa, neste tipo de metodologia é possível dar voz aos próprios deficientes visuais criando a possibilidade de compartilhar suas experiências e anseios. Um dos desafios dos métodos de primeira pessoa é fornecer dados sobre a dimensão qualitativa da experiência presente, sendo inacessível aos métodos de terceira pessoa, restritamente voltados para dados quantitativos e aspectos comportamentais. Os métodos de terceira e primeira pessoa, do ponto de vista científico, produzem dados distintos e de valor complementar (KASTRUP, 2009).

Antes de continuar a explanação sobre tecnologia assistiva para deficientes visuais faz-se necessário considerar a comunicação do deficiente visual também como um tipo de tecnologia assistiva sendo este tema abordado no item seguinte.

\subsubsection{Sistema de escrita em Braile:}

Segundo Nicolaiewsky e Correa (2008), as letras em Braille são formadas a partir da combinação de seis pontos que compõem o que é chamado de cela Braille. A cela é formada por duas colunas e três linhas de pontos. A localização dos pontos são dispostos no sentido de cima para baixo, inicialmente na coluna da esquerda e posteriormente na coluna da direita e sendo denominados respectivamente pontos números $1,2,3,4,5$ e 6 . Cada combinação de pontos em relevo forma, portanto, determinada letra ou sinal de pontuação. A letra c, por exemplo, é formada pelos pontos 1 e 4, como mostra a Figura 1.

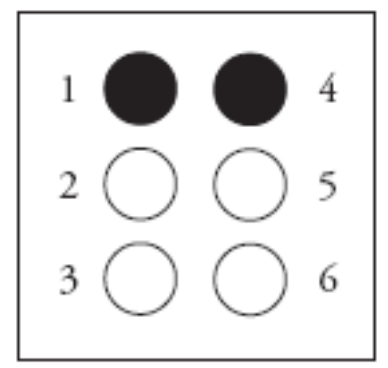




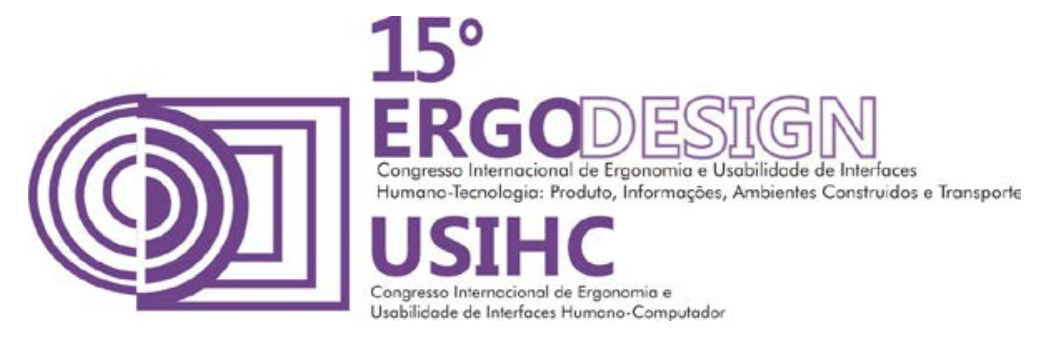

FIGURA1: Cela em Braille. Fonte. NICOLAIEWSKY E CORREA (2008).

As letras em Braille são mais semelhantes entre si do que as letras do sistema impresso, o que torna o sistema Braille mais difícil de ser aprendido (PRING, 1994). A reglete, segundo o manual de escrita da reglete (TECE, 2014), é um instrumento utilizado para escrita manual do Braille. A palavra reglete tem origem na palavra francesa règle que significa régua. Este instrumento é composto por uma régua-guia, uma parte inferior e superior onde a folha é colocada entre elas, para se realizar a escrita em Braile é preciso pressionar um acessório chamado punção nas lacunas da reglete (Figura 2).

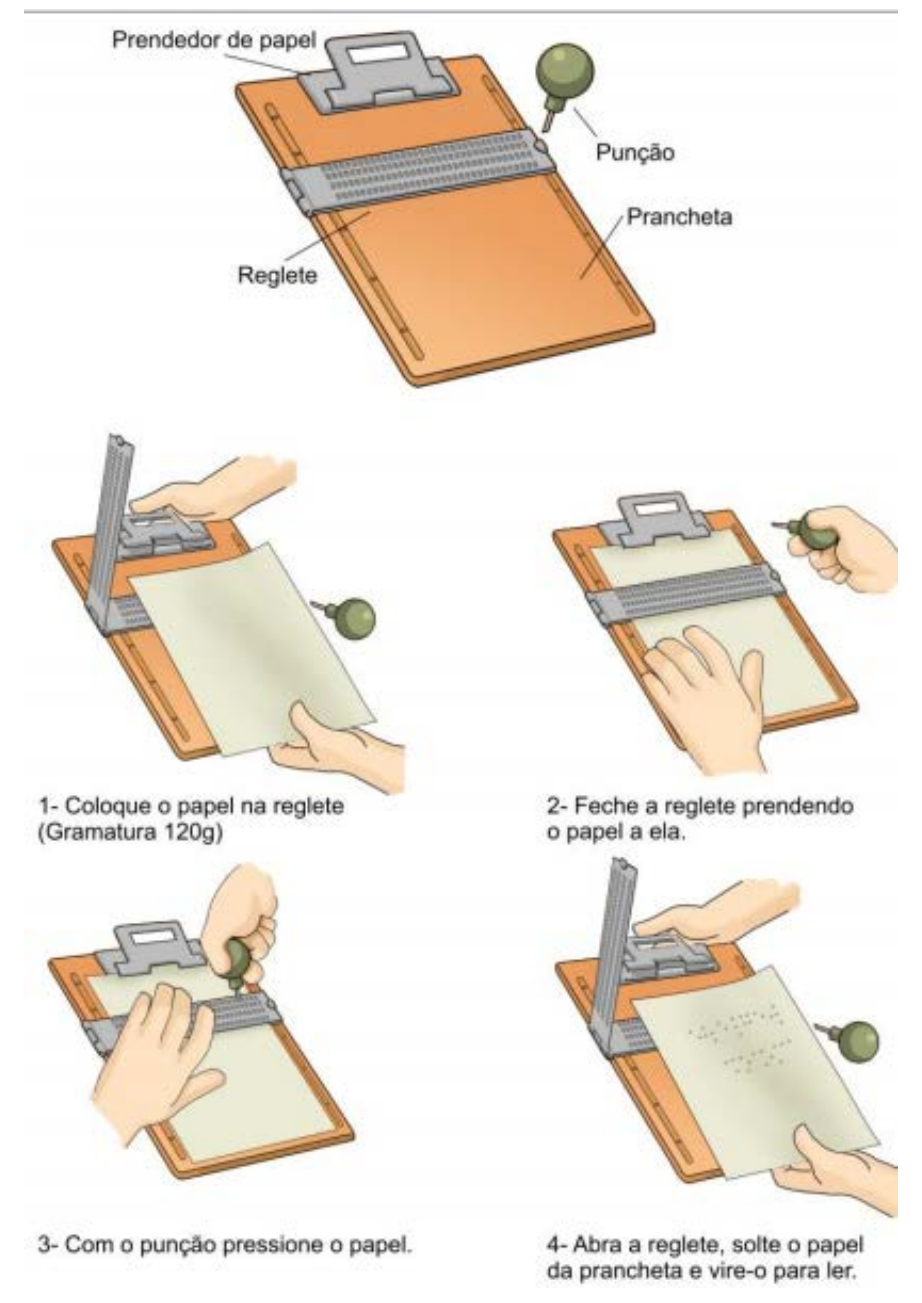




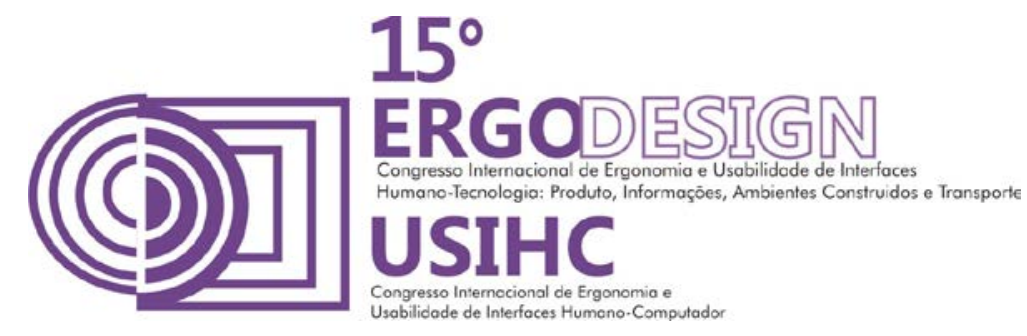

FIGURA 2: Reglete de mesa.Fonte (TECE, 2014)

Nicolaiewsky e Correa (2008), apontam as dificuldades encontradas principalmente pelas crianças no processo de aprendizagem da língua escrita através do sistema Braille. Segundo os autores, as crianças cometem muitos erros nos pontos, seja por confusão na sequência, seja por falta de destreza no uso do punção, além da existência comum de erros em relação à escrita da língua portuguesa e também erros de ordem relativos ao domínio do próprio sistema.

A reglete de mesa (Figura 2) é um aparelho composto por uma prancheta e uma reglete (réguaguia). A reglete de bolso funciona da mesma forma que o modelo de mesa, no entanto é composto apenas da régua-guia e um punção, conforme indicada na figura 3 (TECE, 2014).

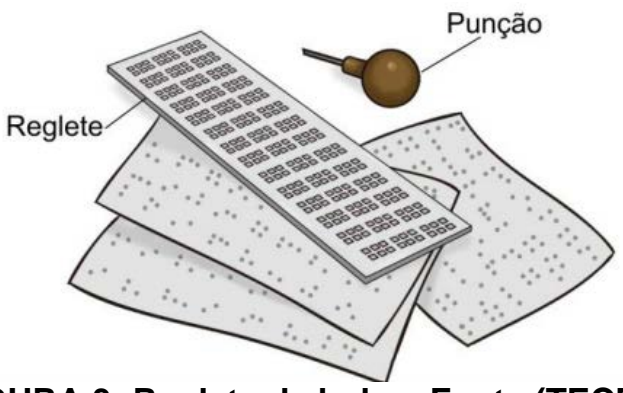

FIGURA 3: Reglete de bolso. Fonte (TECE, 2014).

Tanto a reglete de mesa como a de bolso são classificadas como regletes negativas, pois os pontos são côncavos e a ponta do punção convexa, a escrita em Braille é realizada em baixo relevo, sendo necessária a inversão dos pontos, escrevendo-se da direita para a esquerda conforme demonstrado na figura 4 (TECE, 2014). 


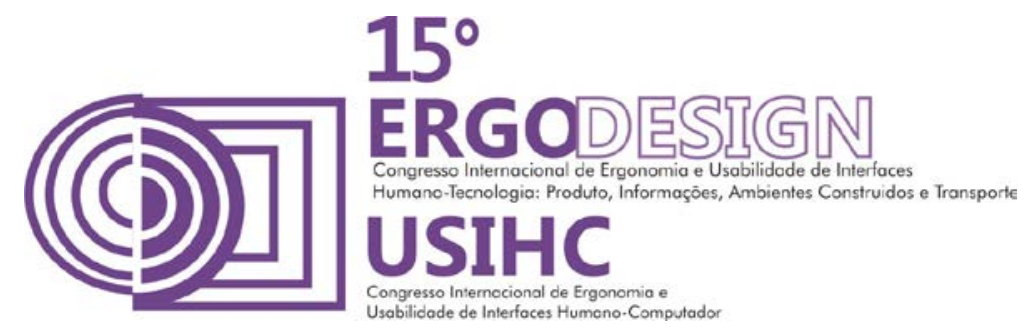

Lê-se assim:

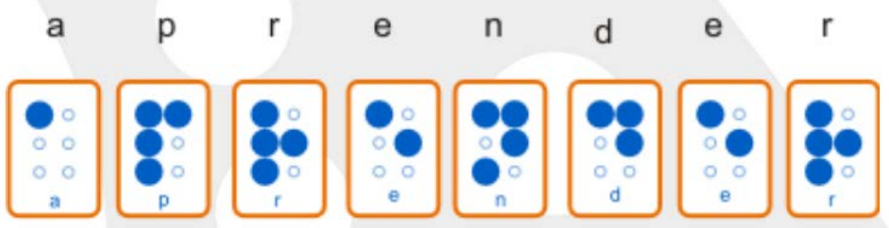

Escreve-se assim:

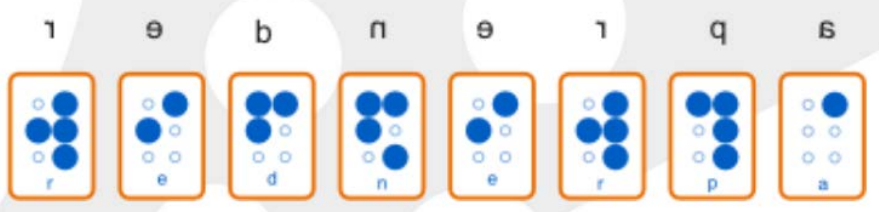

FIGURA 4: Modos de escrita negativa em Braille. Fonte (TECE, 2014).

Já na reglete positiva (figura 5), os pontos estão alto relevo (convexos) e a ponta do punção côncava, a escrita em Braille é realizada em alto relevo, não sendo necessária, a inversão dos caracteres durante o processo de escrita, porem o papel deve ter gramaturura maior ou igual a 120g. Uma outra inovação em relação aos modelos anteriores é que neste sistema é possível escolher dentre 2 tamanhos do punção (TECE, 2014).

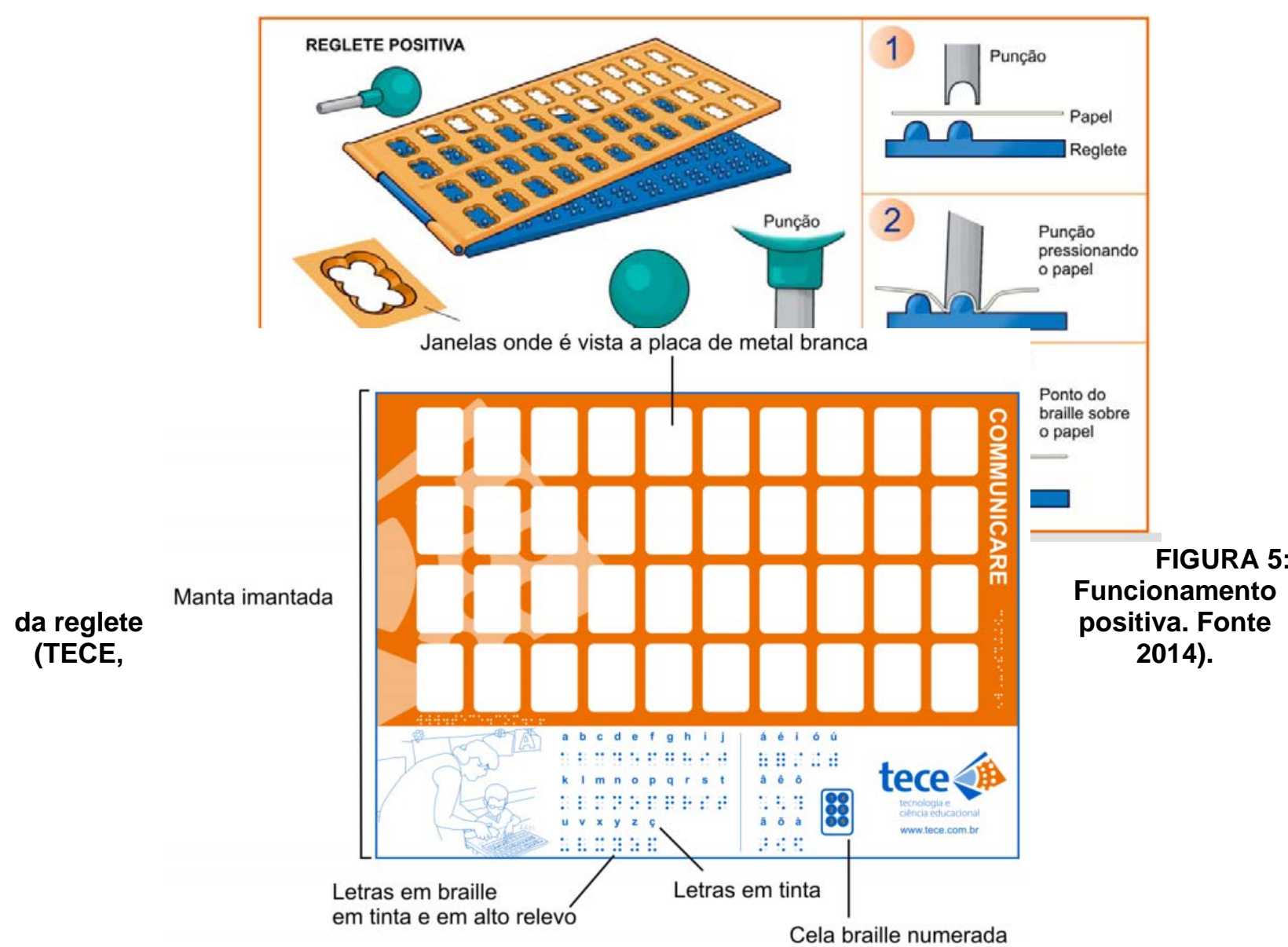




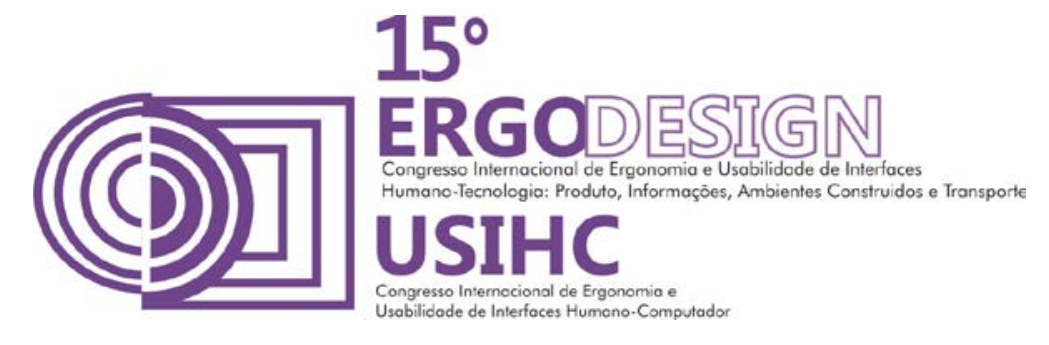

FIGURA 6: Desenho partes principais da lousa Communicare. Fonte (TECE, 2014).

Dispositivo Communicare (figura 6). Esse material foi desenvolvido por uma equipe interdisciplinar, incluindo um designer, para auxiliar professores no o ensino do Sistema Braille. Este material também pode ser utilizado para o ensino de disciplinas como português e cálculos para videntes e deficientes, podendo este ser considerado uma tecnologia assistiva com caráter de um design universal. Para o ensino de Braille, por conter 10 celas (janelas) em cada linha é possível ensinar o braille a partir da lógica usada por Louis Braille (TECE, 2014).

Alpha é um material que auxilia o aprendizado em braile, tendo botões móveis e imatizados é possível ilustrar todas as letras em sua plataforma de metal, Conforme ilustra a figura 7( TECE, 2014).

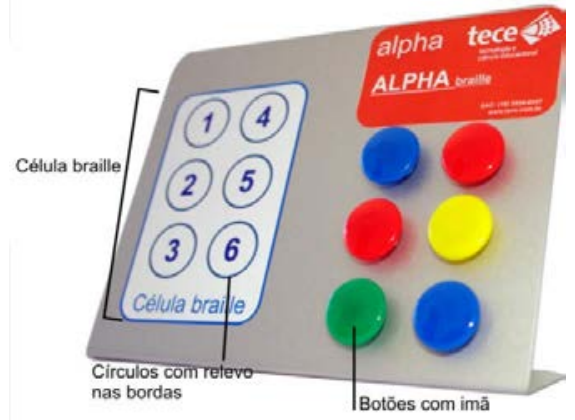

FIGURA 7: Modos de uso do Método Alpha. Fonte. Manual de usa de reglete (TECE, 2014)

O alfabeto braille magnético (figura 8) também trata-se de uma ferramenta projetada para ser utilizada no ensino do sistema Braile, por ser um dominó de números e letras, escrito em braile (alto-relevo) e também à tinta, possibilita que deficientes visuais e videntes possam jogar sem restrições, sendo enquadrado nos quesitos do design universal. 

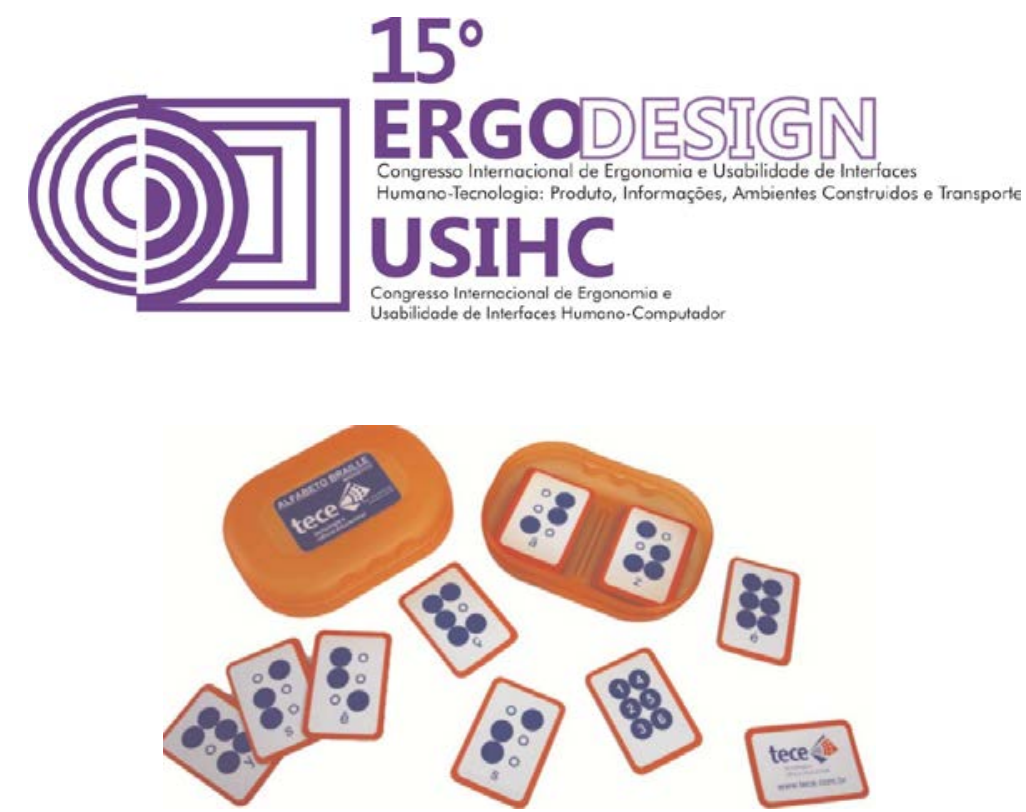

FIGURA 8: Alfabeto em Braille Magnético. Fonte (TECE, 2014).

\subsection{Tecnologia assistiva para deficientes visuais em idade escolar}

O emprego dos recursos de Tecnologia Assistiva é amplamente recomendado para auxiliar o desempenho de escolares com baixa visão. Estes podem ser qualquer recurso ou solução que potencialize o mecanismo visual do indivíduo com baixa visão em suas AVDs (atividades de vida diárias) sendo ordenados em recursos óptico, não óptico, eletrônico e de informática (GASPARETTO et al., 2009).

Recursos ópticos para favorecer o desempenho visual à distância são: os óculos comuns, as lentes de contato, sistemas telescópios manuais de foco ajustável e sistemas telescópios de foco fixo, ambos montados em armação. Telescópio é um aparelho óptico que amplia a dimensão da imagem projetada na retina (fóvea), permitindo que o escolar visualize a lousa também podendo ser utilizado em situações extra classe, para visualizar placas, nome de ruas e assistir televisão (CARVALHO et al., 2002).

Segundo Carvalho et al. (2005) os aparelhos ópticos para visão proximal (perto) abrangem óculos comuns e óculos especiais com lentes convexas, lupas manuais, fixas e de apoio. Para escolares, o emprego dos recursos ópticos favorece o desempenho visual e rendimento em relação à leitura de textos, escrita e à cópia da lousa.

Os recursos ópticos podem ser utilizados separadamente ou em conjunto com os recursos não ópticos, sendo estes adequações de objetos e ambientes que proporcionam uma melhor eficácia visual (CARVALHO et al., 2005). Os recursos não ópticos são soluções simples como letras grandes em livros didáticos, cadernos com linhas mais espaçadas, aumento da iluminação do local de estudo, aumento do contraste entre cores de materiais didáticos, utilização de lápis com grafite mais forte, canetas hidrográficas, uso de cores bem contrastantes também na escrita da lousa (GASPARETTO, 2010).

\subsubsection{Recursos de informática em Tecnologia Assistiva para deficientes visuais}

Outras ferramentas eficazes no auxílio de escolares com baixa visão são os recursos da informática, podendo ser empregado copiosamente no âmbito escolar e ambientes extra sala, interagindo por meio de interfaces visuais, sonoras, táteis ou comcomitantes. Os softwares de ampliação de tela são os mais comuns e agem como uma lupa virtual, permitindo o acesso à informática. Outras opções são os leitores de tela, que ao serem instalados permitem acesso a outros aplicativos e ao sistema operacional (MORTIMER, 2010). 


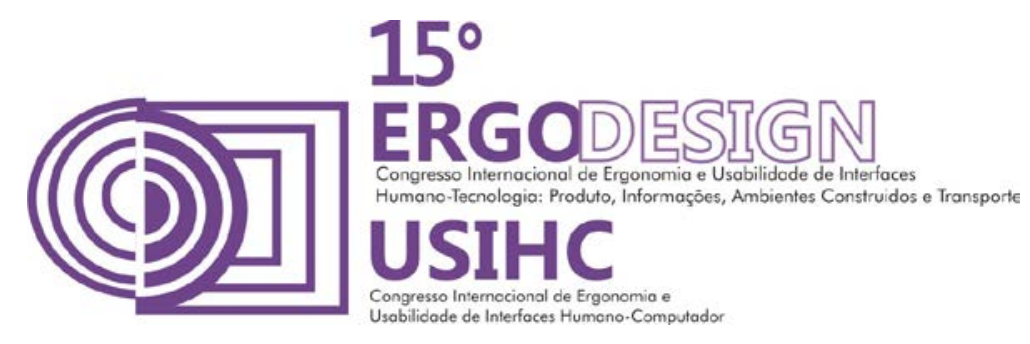

O dispositivo BrainPort ${ }^{\circledR}$ foi encontrado como a versão atualmente mais evoluída do TVSS (Tactile-Vision-Substitution-System) ou seja, sistema de substituição sensorial tátil. Trata-se de um sistema que transforma as características de uma modalidade sensorial (falha, no caso a visão) em estímulos de outra modalidade sensorial ativa neste caso a tátil. Esse sistema foi desenvolvido para o auxílio na locomoção e na identificação de objetos para deficientes visuais nos anos 60, pela equipe do Prof. Paul Bach-y-Rita, na Califórnia. Pode-se esquematizar a composição do TVSS em quatro elementos: uma microcâmera que tem a função de converter a energia luminosa em sinais elétricos; um sistema informático constituído por um computador, podendo ou não se substituir pela câmera; uma caixa de conversão que transforma o sinal visual captado pela câmera em sinal tátil; e uma matriz de estimulação elétrica ou mecânica (KASTRUP, 2009).

Radar Tátil (RT), elaborado na Universidade de Tóquio pelo professor Álvaro Cassinelli, trata-se de um dispositivos de substituição sensorial para o desempenho locomotor de indivíduos cegos. O Radar Tátil (RT) é constituído como uma faixa de cabeça na qual estão dispostos cinco módulos de telêmetro infravermelho (medidor de distância), três módulos estão situados na região do lobo frontal e dois na região dos lobos temporais. Quando os telêmetros captam algum obstáculo no ambiente, os módulos vibram estimulando a região cutânea sobre a qual estão afixados, indicando simultaneamente ao deficiente visual a direção e a proximidade na qual se encontram os obstáculos a serem evitados, na distância de aproximadamente $80 \mathrm{~cm}$ (GUSMÃO, 2012).

\subsection{Modelos de tecnologia assistiva para deficientes visuais em telefonia móvel}

O smartphone Ray G300 (Figura 9.a) é o primeiro sistema de apoio completo projetado especialmente para cegos e deficientes visuais; possui hardware da Huawei e sistema operacional baseado em Android. A interface gráfica foi projetada para que a operação pudesse ser mediadas pelos dedos, com apenas um gesto (interface homogênea). O feedback é dado pela voz e por vibração. Os recursos oferecido pelo sistema são: reconhecimento de imagens (transcrição da imagem capturada pela câmera); identificação do valor de moeda; reconhecimento de cor ; serviço de assinatura de revistas e livros com conteúdo em áudio; serviço de lista de contatos; leitura de mensagens SMS com o recurso Text-To-Speech e anúncio de localização via GPS (ZILBERMAN, 2014).
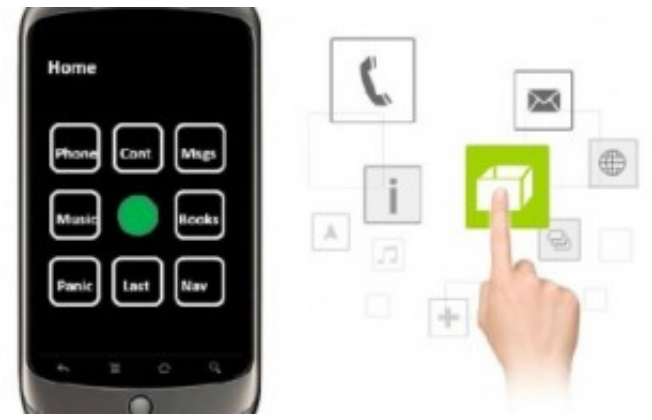

a

b

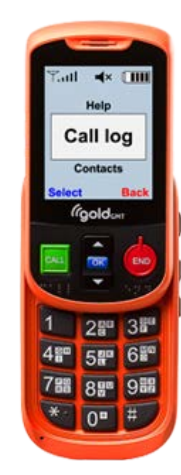




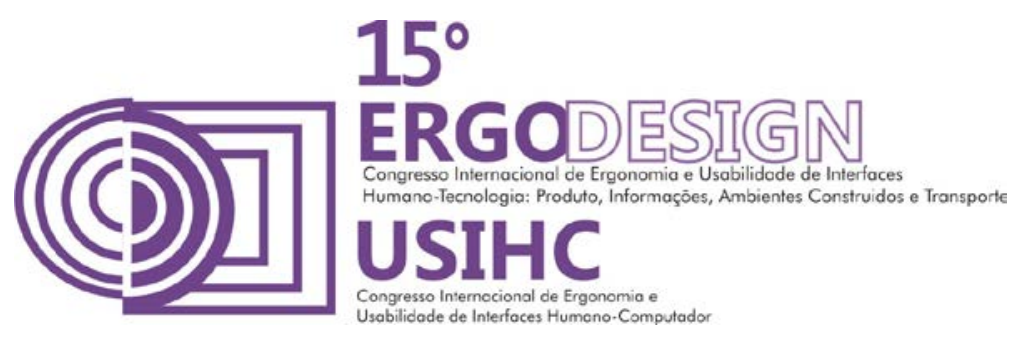

FIGURA 9: Ray C300(a); Odin Mobile(b). Fonte. ZILBERMAN, 2014; OdinMobile.com

O sistema Odin Mobile (figura 9.b) trata-se de um serviço de telefone celular para cegos e pessoas com baixa visão. Cada aparelho vem com um widget na tela inicial, desenvolvido pela Odin Móvel, que possui oito aplicações desenvolvidos para usuários cegos. Ao tocar no aplicativo que se deseja, o Nexus 5 ajudará a instalar o aplicativo no dispositivo. No Modelo Odin VI, o teclado tem botões de grandes dimensões (figura 9), para garantir a facilidade de uso, e os menus são simples e fácil de navegar. Os botões de controle são diferentes cores e formas. O sistema ODIN VI se comunica em várias línguas diferentes destre elas o inglês, línguas europeias, espanhol e francês. (ODINMOBILE, 2014)

O TapTapSee é um aplicativo projetado para auxiliar os cegos e pessoas com baixa visão a identificar objetos que encontram em suas vidas diárias. Ao fotografar um objeto, o dispositivo identifica sonoramente o mesmo. Desenvolvido para o sistema iOS 7.0 ou posterior, compatível com iPhone, iPad e iPod touch, podendo ser otimizado para iPhone 5 (ESPM, 2014).

\section{CONSIDERAÇÕES FINAIS}

Tendo em vista a grande porcentagem de Brasileiros que possui algum tipo de deficiência visual que, segundo o senso de 2010 é $18.6 \%$, estudos sobre tecnologia assistiva para este público no Brasil são ainda insuficientes. Existe muito o que fazer para que a tão aclamada inclusão aconteça de fato, principalmente no âmbito escolar. Este estudo apresentou algumas poucas alternativas de tecnologia assistiva para deficientes visuais encontadas no Brasil, tais como: ferramentas para auxiliar a escrita em Braille, software para ampliação de letras e imagens, dispositivos que transformam letras em sons (tradução), sinais visuais em elétricos, aplicativos para celulares que fotografa um objeto e soletra o respectivo nome. Apesar das contribuições destes sistemas, ainda há uma grande carência de ferramentas, objetos, software, artefatos que facilitem a independência de pessoas com deficiência visual, de forma a garantir a inclusão desta população no âmbito da social, bem como no ambiente escolar. Neste contexto, o Design aplicado à Tecnlogia Assistiva tem potencial para desempenhar um papel decisivo na garantia da plena inclusão e participação social destas pessoas. O profissional de Design, atuando em uma equipe interdisciplinar, deve buscar o envolvimento e a preocupação em atender às necessidades deste grupo com necessidades especiais.

\section{REFERÊNCIAS BIBLIOGRÁFICAS}

ARRUDA, S.M.C.P. Percepções da auto-eficácia nas atividades de vida diária e qualidade de vida de estudantes com baixa visão ou cegueira. 2005. 163f. Tese (Doutorado em Ciências Médicas)Faculdade de Ciências Médicas, Unicamp, Campinas, 2006.

BONSIEPE, Gui e outros. Metodologia Experimental: Desenho Industrial. Brasília: CNPq/Coordenação Editorial, 1986.

CAMBIAGHI, Silvana Serafino. Desenho Universal - métodos e técnicas para arquitetos e urbanistas. São Paulo: Editora Senac São Paulo, 2007.

CARVALHO, K.M.M. et al. Avaliação e conduta em escolares portadores de visão subnormal atendidos em sala de recursos. Arq. Bras. Oftalm., São Paulo, v.65, n.4, p.445-449, 2002. 


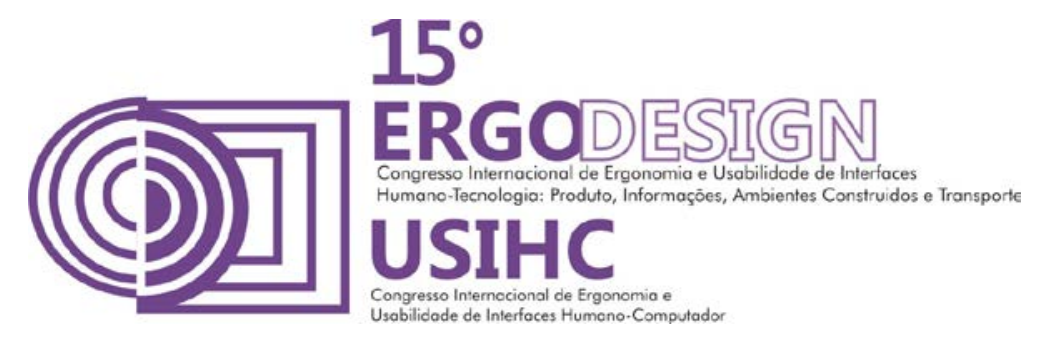

ESPM. Portal Jornalismo. Aplicativo para celulares identifica objetos para deficientes visuais. 2014, Disponível em < http://jornalismosp.espm.br/geral/aplicativo-identifica-objetos-para-deficientes-visuais> acessos 4 dez, 2014.

FRANCISCO P. C. M. MENEZES A. M. Design universa. Rer.Construindo, Belo Horizonte, v.3, n.1, p.25-29, jan./jun. 2011. Disponível em < file:///C:/Users/Be/Downloads/1763-3196-1-SM.pdf>. Acessos em 13 dez. 2014.

GARCÍA J.C.D.; GALVÃO T.A.F. Pesquisa nacional de tecnologia assistiva. Instituto de Tecnologia Social. São Paulo. ITS Brasil, 2012.

GUARNIERO, G. (1977). Tactile vision: A personal view. Journal of Visual Impairment \& Blindness, $71,125-130$

GASPARETTO, M.E.R.F. et al. Uso de recursos de tecnologia assistiva na educação municipal, estadual e federal tecnológica. In: BRASIL. Subsecretaria nacional de promoção dos direitos da pessoa com deficiência. Comitê de Ajudas Técnicas. (Org.). Tecnologia Assistiva, Brasília: Corde, p.41-58, 2009.

Orientações ao professor e à comunidade escolar referentes ao aluno com baixa visão. In: GUSMÃ̃ B.P.G.R.; Dispositivos de substituição sensorial podem favorecer a locomoção autônoma dos cegos? 2012.71 f. Dissertação (Mestrado em Psicologia) - Instituto de Psicologia, Universidade Estadual do Norte Fluminense Darcy Ribeiro - Campus dos Goytacazes, Rio de Janeiro. 2012.

IBGE, Instituto Brasileiro de Geografia e Estatística. Censo Demográfico 2010. Disponível em http://www.ibge.gov.br/home/estatistica/populacao/censo2010. acessos em 4 dez. 2014.

KASTRUP, Virgínia et al . O aprendizado da utilização da substituição sensorial visuo-tátil por pessoas com deficiência visual: primeiras experiências e estratégias metodológicas. Psicol. Soc., Florianópolis , v. 21, n. 2, ago. $2009 \quad$ Disponível em <http://www.scielo.br/scielo.php?script=sci arttext\&pid=S0102-71822009000200013\&lng=pt\&nrm=iso> . acessos em 11 dez. 2014. http://dx.doi.org/10.1590/S0102-71822009000200013.

MORTIMER, R. Recursos de informática para a pessoa com deficiência visual. In: SAMPAIO, M.W. et al. (Org.).Baixa visão e cegueira: os caminhos para a reabilitação, a educação e a inclusão. Rio de Janeiro: Cultura Médica, Guanabara Koogan, 2010, p. 221-231.

NICOLAIEWSKY, Clarissa de Arruda; CORREA, Jane. Escrita ortográfica e revisão de texto em Braille: uma história de reconstrução de paradigmas sobre o aprender. Cad. CEDES, Campinas, v. 28, n. 75, ago. 2008 . Disponível em <http://www.scielo.br/scielo.php?script=sci_arttext\&pid=S010132622008000200006\&lng=pt\&nrm=iso>. acessos em 14 dez. 2014. http://dx.doi.org/10.1590/S010132622008000200006.

ODIN MOBILE. Aplicativo para celular de tecnologia assistiva para deficientes visuais. Disponível em < http://odinmobile.com>. acessos em 5 dez. 2014

ORGANIZAÇÃO MUNDIAL DE SAÚDE (OMS). CID- 10. Classificação estatística internacional de doenças e problemas relacionados à saúde. 9. ed. rev. São Paulo: EDUSP, 2003.

Phillips, B., \& Zhao, H. (1993). Predictors of assistive technology abandonment. Assistive Technology, 5(1), 36-45.

PRING, L. Touch and go: learning to read Braille. Reading Research Quarterly, v. 29, p. 67-74, 1994. RAY. Aplicativo para celular de tecnologia assistiva para deficientes visuais. Disponível no sistema Android http://www.project-ray.com/blog https://play.google.com/store/apps/details?id=com.ray.manager. acessos em 5 dez. 2014 


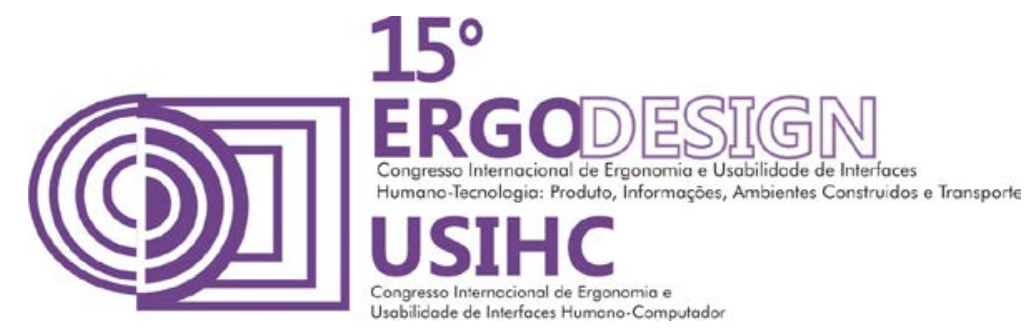

RIEMER-REISS, M. \& WACKER, R. R. (2000). Factors associated with assistive technology discontinuance among individuals with disabilities. Journal of Rehabilitation, 66(3), 44-50.

TAPTAPSEE. Aplicativo para celular de tecnologia assistiva para deficientes visuais. Disponível $<$ https://itunes.apple.com/br/app/taptapsee-blind-visually-impaired/id567635020?mt=8> . acessos em 5 dez. 2014

ROCHA, E. F.; CASTIGLIONI, M. C. Reflexões sobre recursos tecnológicos: ajudas técnicas, tecnologia assistiva, tecnologia de assistência e tecnologia de apoio. Rev. Ter. Ocup. Univ. São Paulo, v. 16, n. 3, p.97-104, set./dez., 2005.

SAMPAIO, M.W. et al. (Org.). Baixa visão e cegueira: os caminhos para a reabilitação, a educação e a inclusão. Rio de Janeiro: Cultura Médica, Guanabara Koogan, 2010. p.347-360.

TECE. Tecnologia e Sistema Educacional . Manual de uso de Regletes. do sonho a estratégia: um caminho coletivo. Rio Claro. $20014 . \quad$ Disponível em < http://www.tece.com.br/painel/uploads/Manual\%20de\%20uso\%20de\%20produtos regletes\%20communic are\%20alpha\%20e\%20alfabeto.pdf>. acessos em 10 dez. 2014.

Thompson, E., Lutz, A., \& Cosmelli, D. (2005). Neurophenomenology: an introduction for neurophilosophers. In A. Brook \& K. Akins (Orgs.), Cognition and the brain: the philosophy and neuroscience movement (pp. 40-97). Cambridge: Cambridge University Press.

VARELA, F.;SHEAR, J. (1999). First-person accounts: why, what, and how. Journal of Consciousness Studies, 6(2-3), 1-14.

ZILBERMAN,B. Projeto Ray. 2014. Disponível em < http://www.pletz.com/blog/israelenses-criamsmartphone-para-deficientes-visuais/>. acessos em 4 dez. 2014.

Agradecimentos: CNPQ (Conselho Nacional de Pesquisa); CAPES (Coordenação de Aperfeiçoamento de Pessoal de Nível Superior) 